Sharif University of Technology
Scientia Iranica
SCIENTIA
I RAN ICA
http://scientiairanica.sharif.edu

\title{
Investigation of moisture susceptibility of SBS modified asphalt containing alumina trihydrate by static contact angle measurements
}

\author{
Sh. Liu ${ }^{\mathrm{a}, *}$, Sh. Zhou ${ }^{\mathrm{b}}$, and Y. Xu ${ }^{\mathrm{c}}$ \\ a. College of Civil and Transportation Engineering, Hohai University, Nanjing, Jiangsu, 210098, China. \\ b. Guangxi Transportation Research Institute, Nanning, No. 6, Gaoxin Road, Nanning, Guangxi, 530007, China. \\ c. Zhejiang Scientific Research Institute of Transport, Gangyang road, 188, Linan, Hangzhou, Zhejiang, 310006, China. \\ Received 30 September 2017; received in revised form 24 November 2017; accepted 5 February 2018
}

\author{
KEYWORDS \\ Asphalt binder; \\ Flame retardant; \\ Contact angle; \\ Surface free energy; \\ Moisture \\ susceptibility.
}

\begin{abstract}
Although several studies have been carried out to assess the performance of asphalt mixture with the addition of alumina trihydrate (ATH) as a flame retardant, the moisture susceptibility of asphalt mixture containing ATH is still not fully clear. In this study, the moisture susceptibility of binders containing ATH was assessed through the Surface Free Energy (SFE) obtained by the sessile drop method. A commonly used StyreneButadiene-Styrene (SBS) modified asphalt with different dosages $(0 \%, 6 \%, 8 \%, 10 \%, 12 \%$, and $14 \%$ ) of ATH was prepared to determine the physical properties, flame retardancy, and SFE parameters. Experimental results indicated that the addition of ATH increased the viscosity, softening point, $G^{*} / \sin \delta$, and limiting oxygen index, but decreased any possible penetration and ductility. In addition, an increase in total SFE, cohesive energy, and work of adhesion was observed with the addition of ATH. Conversely, the work of debonding, wettability, and energy ratio decreased due to the addition of ATH. It was concluded that the ATH had a significant negative effect on the moisture-induced damage potential of asphalt mixture in terms of micromechanisms. The recommended percentage of ATH was $6-8 \%$ regarding physical properties, flame retardation, and moisture susceptibility.
\end{abstract}

(C) 2019 Sharif University of Technology. All rights reserved.

\section{Introduction}

Tunnels have become one of the most effective methods to shorten travel mileage and reduce the pressure on ground transportation, which are vital for maintaining transport infrastructure. In China, a growing number of tunnels have been built to connect networks so that

\footnotetext{
*. Corresponding author. Tel.: +8602583787606 $+8613611584498$

E-mail addresses: lsjwork@hhu.edu.cn, \&lsjwork@126.com (Sh. Liu); zhoushengbo2005@163.com (Sh. Zhou); xys0613@126.com (Y.Xu)
}

doi: $10.24200 /$ sci. 2018.5286 .1185 the environment can be protected or the destruction pace of the mountain can be reduced [1]. Based on the data of the Comprehensive Planning Division of the Transportation Department, China [2,3], the development of the tunnel construction has been quick over the last decade. Furthermore, the length and number of tunnels in 2015 reached $14000 \mathrm{~km}$ and 12000 , respectively. Many catastrophic fires have occurred in the semi-enclosed space of a long highway tunnel over the recent years all over the world that have led to significant structural damages and, even, loss of lives due to the toxic smoke production and the difficulty of rescue missions. Inevitably, tunnel fire is also difficult to prevent in China. According to a survey, many 
shocking road tunnel fires have occurred over the past decades [4-6]. Thus, with due consideration of the high risk of fire, it is necessary to improve material properties or choose suitable materials when the tunnel pavement is done [7].

Due to the disadvantages such as slow construction, difficulty in maintenance, and high noise level of rigid pavements, asphalt pavements are applied widely to roads and tunnels. In China, with the rapid increase of the tunnel number and mileage, asphalt mixture as the paving material has been gradually adopted for many large-scale road tunnels $[8,9]$. However, since asphalt is a type of hydrocarbon, it is easy for it to ignite if an accident occurs in a tunnel, especially one involving a fire [10-12]. This causes asphalt to burn and release large amounts of smoke and toxic gases, impeding the traffic flow and hampering rescue operations. Related technologies used for improving the flame retardant of asphalt have gradually attracted the attention of researchers and become a widely accepted concept $[13,14]$. In recent years, the addition of flame retardants to asphalt has proven to be a successful popular measure for preventing the asphalt from burning (or pyrolysis) [15]. There are currently many flame-retardant types such as Magnesium Hydroxide $(\mathrm{MH})$, decabromodiphenyl oxide (DBDPO), decabromodiphenyl ethane (DBDPE), alumina trihydrate $(\mathrm{ATH})$, antimonous oxide $\left(\mathrm{Sb}_{2} \mathrm{O}_{3}\right)$, ammonium polyphosphate (APP), and pentaerythritol (PER) [16]. Considering the advantages of cost-effectiveness, safe handling, and environmentally friendliness, alumina trihydrate (ATH) has become the most widely used flame retardant to weaken or prevent the burning behavior of asphalt in the world [17].

Previous studies have been conducted to study flame-retardant properties, including the flameretardant performance $[18,19]$, the aging characteristic of flame-retardant asphalt [20], the design method of asphalt mixture [21], and the effect of flame retardant on the pavement performance $[2,22]$. In addition, the thermal gravimetric analysis and infrared spectrum (IR spectrum) were also carried out to determine and analyze the thermal degradation behavior of FlameRetardant (FR) asphalt materials [23-25]. In short, most of the FR asphalt tests have been carried out to analyze the properties of rheological behaviors, pavement performance, and reaction mechanism. Several studies have reported that FR additives could weaken the water stability of asphalt mixture through the Marshall stability, loss of Marshall stability test, and freeze-thaw split test $[26,27]$. However, according to existing reports, the correlation between field observations and the above-mentioned evaluation methods of water stability is not consistent. In particular, the evaluation methods of water damage from the viewpoint of asphalt mixture could not reflect the water damage mechanism $[28,29]$. Therefore, it is not very clear how the FR influences the moisture damage of asphalt and asphalt mixture.

In general, moisture damage of asphalt mixture is caused by cohesive failure and adhesive failure, resulting from the reduction of bond strength of asphalt and the bonding failure of the asphalt-aggregate system under wet conditions [30]. Many theories have been developed so far to explain and evaluate the water damage mechanism [31,32]. Accordingly, one of the theories is Surface Free Energy (SFE) that is used widely and successfully to evaluate the moisture susceptibility of asphalt mixture and determine the asphalt binders' cohesive strength and adhesion strength of asphaltaggregate based on micro-mechanisms [33,34]. The purpose of this research is to investigate the moistureinduced damage potential of binders containing ATH flame retardants through the SFE method. The physical and flame-retardant properties are first tested to analyze the characteristics of asphalt containing ATH. Then, the components of SFE of tested binders are obtained through the sessile drop method. Finally, SFE parameters of asphalt-aggregate systems containing different $\mathrm{ATH}$ contents and aggregate types are calculated to evaluate moisture susceptibility.

\section{Material and methods}

\subsection{Raw materials}

In this experiment, SBS modified asphalt was selected as the matrix asphalt to blend with flame-retardant additives. The conventional test was carried out to characterize the properties of the matrix asphalt, the results of which are shown in Table 1. The aluminum trihydrate (ATH) of mico AH-2 was selected and used in this study as the flame retardant, whose related properties are illustrated in Table 2 .

In order to estimate the moisture susceptibility of the asphalt-aggregate system containing various dosages of ATH, three widely used aggregates for asphalt mixture in Jiansu Province, China were collected and tested in this study. Table 3 shows the SFE components of the selected limestone, basalt, and granite.

Three commonly used probe liquids, such as

Table 1. Properties of the asphalt binders.

\begin{tabular}{ll}
\hline \multicolumn{1}{c}{ Test properties } & \multicolumn{1}{c}{$\begin{array}{c}\text { SBS modified } \\
\text { bitumen }\end{array}$} \\
\hline $25^{\circ} \mathrm{C}$ penetration & $53.6(0.1 \mathrm{~mm})$ \\
$15^{\circ} \mathrm{C}$ ductility & $34.3(\mathrm{~cm})$ \\
Softening point (TR \& B) & $68.7\left({ }^{\circ} \mathrm{C}\right)$ \\
$15^{\circ} \mathrm{C}$ density & $1.033\left(\mathrm{~g} / \mathrm{cm}^{3}\right)$ \\
Solubility (trichloroethylene) & $99.7(\%)$ \\
\hline
\end{tabular}


Table 2. Properties of the flame-retardant ATH.

\begin{tabular}{ccccccccc}
\hline $\begin{array}{c}\text { Test } \\
\text { properties }\end{array}$ & $\mathrm{Al}_{2} \mathrm{O}_{3}$ & $\mathrm{SiO}_{2}$ & $\mathbf{F e}_{2} \mathrm{O}_{3}$ & $\mathrm{Na}_{2} \mathrm{O}$ & $\begin{array}{c}\text { Loss on } \\
\text { ignition }\end{array}$ & $\begin{array}{c}\text { Particle } \\
\text { size }\end{array}$ & $\mathbf{P H}$ & $\begin{array}{c}\text { Adhesive } \\
\text { water }\end{array}$ \\
\hline Results & $64 \%$ & $0.03 \%$ & $0.01 \%$ & $0.3 \%$ & $34 \pm 0.5 \%$ & $3 \mu \mathrm{m}$ & 8.5 & $0.5 \%$ \\
\hline
\end{tabular}

Table 3. Surface free energy components of aggregates $\left(\mathrm{mJ} / \mathrm{m}^{2}\right)$.

\begin{tabular}{cccc}
\hline Aggregates & $\gamma^{\mathrm{LW}}$ (Lifshitz-van der Waals) & $\boldsymbol{\gamma}^{\mathrm{AB}}$ (acid base) & $\boldsymbol{\gamma}$ (total SFE) \\
\hline Limestone & 8.01 & 48.17 & 56.19 \\
Basalt & 7.86 & 44.98 & 52.84 \\
Granite & 7.07 & 48.55 & 55.62 \\
\hline
\end{tabular}

Table 4. SFE components of probe liquids $\left(\mathrm{mJ} / \mathrm{m}^{2}\right)$.

\begin{tabular}{cccc}
\hline Probe & $\boldsymbol{\gamma}^{\text {LW }}$ (Lifshitz-van der Waals) & $\boldsymbol{\gamma}^{\mathrm{AB}}$ (acid base) & $\boldsymbol{\gamma}$ (total SFE) \\
\hline Distilled water & 18.7 & 53.6 & 72.3 \\
Formamide & 39.4 & 19.6 & 59.0 \\
Glycerol & 28.3 & 36.9 & 65.2 \\
\hline
\end{tabular}

distilled water, glycerol, and formamide, were used to measure and calculate the contact angle with tested binders. Table 4 shows the SFE components of the selected probe liquids.

\subsection{Preparation of binders}

To prepare the flame-resistant asphalt binders, the SBS modified bitumen was heated to $165^{\circ} \mathrm{C}$ in an iron container to make it flow first. Then, different dosages of ATH ( $0 \%$ wt. and $6 \%-14 \%$ wt. with $2 \%$ incensement) were poured into the liquid matrix asphalt to prepare the tested samples using a high shear mixer. The shear time lasted for $20 \mathrm{~min}$ at $165^{\circ} \mathrm{C}$ at a rotational speed of $4000 \mathrm{rpm}$ to promote the interaction between ATH additive and binders. Finally, the asphalt samples are placed out in the air to cool back to ambient temperature for the follow-up tests.

\subsection{Experimental program}

\subsubsection{Performance test of asphalt}

In this study, conventional tests, including penetration, ductility, and softening point, were carried out in accordance with the procedures of T0604-2011, T06062011, and T0605-2011 in JTG E20-2011 [35]. The viscosities of the binders were also evaluated at $135^{\circ} \mathrm{C}$ by a Brookfield Rotational Viscometer (RV) according to T0625-2011 in JTG E20-2011 [35].

The rutting resistance performances of the asphalt samples were characterized by the rutting factor $\left(G^{*} / \sin \delta\right)$ at a frequency of $10 \mathrm{rad} / \mathrm{s}$ (almost $1.6 \mathrm{~Hz}$ ) using the Dynamic Shear Rheometer (DSR). The test temperatures were set in a range of $58-82^{\circ} \mathrm{C}$ at $6^{\circ} \mathrm{C}$ increment according to ASTM D 7175.

The flame-retardant properties of asphalt can be evaluated using minimum oxygen concentration, which allows asphalt to burn, while the Limiting Oxygen Index (LOI) is determined as the characteristic index. According to ASTM D-2863, the samples size for LOI is $11 \mathrm{~cm} \times 6.5 \mathrm{~cm} \times 0.3 \mathrm{~cm}$.

\subsubsection{Fundamentals of surface free energy and contact angle test}

In general, the SFE is constituted by a sum of LifshitzVan der Waals component and acid-base component based on the acid-base theory, which is also called Van Oss Chaudhury-Good approach [36]. According to the research of Cheng et al. [37], the SFE can be expressed as in Eqs. (1) and (2), when the materials are both liquid and solid:

$$
\begin{aligned}
& \gamma_{l}=\gamma_{l}^{L W}+\gamma_{l}^{A B}, \\
& \gamma_{s}=\gamma_{s}^{L W}+\gamma_{s}^{A B},
\end{aligned}
$$

where $\gamma$ is the total SFE; subscripts $l$ and $s$ stand for the test materials which are solid and liquid, respectively. Superscript $L W$ and $A B$ stand for the SFE components which are Lifshitz-Van der Waals component and acid-base component for the test materials, respectively.

Owens and Wendt [38] put forward Eq. (3) to determine interaction energy $\left(\gamma_{l s}\right)$ between liquid and 


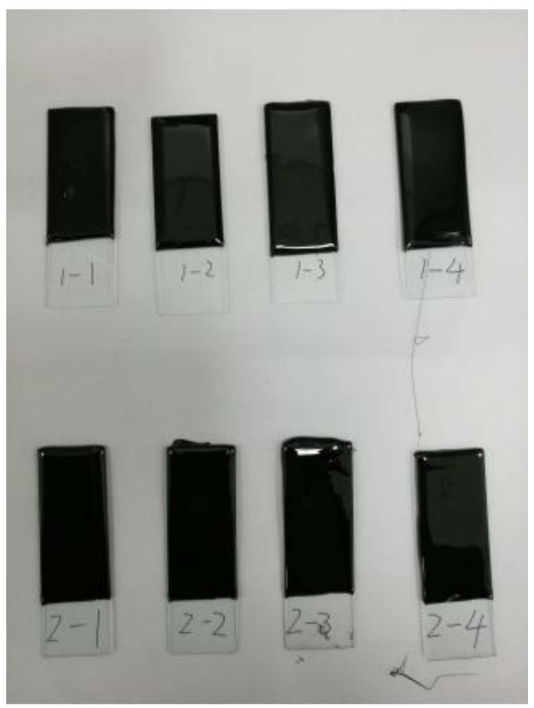

Figure 1. Asphalt binder samples prepared using glass slides.

solid materials as follows:

$$
\gamma_{l s}=\gamma_{s}+\gamma_{s l}-2 \sqrt{\gamma_{s}^{L W} \gamma_{l}^{L W}}-2 \sqrt{\gamma_{s}^{A B} \gamma_{l}^{A B}}
$$

The relationships among the contact angle $(\theta)$, SFE of liquid or solid $\left(\gamma_{l}\right.$ or $\left.\gamma_{s}\right)$, and interaction energy of liquid-solid $\left(\gamma_{l s}\right)$ can be determined using the Young equation, as in Eq. (4):

$$
\gamma_{l} \cos \theta=\gamma_{s}-\gamma_{s l} \text {. }
$$

Reinforced by Eqs. (1)-(4), Eq. (5) can establish the relationship between the contact angle and SFE components. Therefore, if the SFE components of probe liquids are known, each component of the binders can be calculated through the measured contact angle with probe liquids.

$$
\frac{1+\cos \theta}{2} \frac{\gamma_{l}}{\sqrt{\gamma_{l}^{L W}}}=\sqrt{\gamma_{s}^{A B}} \times \sqrt{\frac{\gamma_{l}^{A B}}{\gamma_{l}^{L W}}}+\sqrt{\gamma_{s}^{L W}} .
$$

Based on previous surveys [39], the SFE components and cohesion energy of asphalt, the work of adhesion (under dry condition), work of debonding (under wet condition), wettability, and energy ratio were considered to evaluate moisture susceptibility of asphalt binders containing ATH additive.

In this study, the sessile drop method was used to obtain the contact angles using distilled water, glycerol, and formamide liquids by the equipment of Drop Shape Analyzer 10. The samples were prepared using $25 \times$ $50 \mathrm{~mm}$ glass slides (Figure 1); after the asphalt was heated into fluidity, the glass slide was inserted into and withdrawn quickly from the tested asphalt.

To obtain reliable experimental results, three replicates were measured and compared in the laboratory. The average value was computed to represent the experimental result. The experimental structure of this study is illustrated in Figure 2.

\section{Results and discussion}

\subsection{Physical properties and flame-retardant data}

The values of penetration, softening point, ductility, and viscosity of asphalt samples are plotted versus the ATH contents, and the results are shown in Figure 2(a)(d), respectively. It can be found that the penetration and ductility of binders decrease with the increase of ATH content. For instance, the penetration value of the SBS modified binder (control binder) was found to be 58.6 , while it decreased by about $6 \%, 7.5 \%, 8.9 \%$, $11.1 \%$, and $12.9 \%$, respectively, when ATH contents of $6 \%, 8 \%, 10 \%, 12 \%$, and $14 \%$ were added to the binders. Similarly, the ductility underwent an $8 \%$ decrement. This indicates that ATH modification of asphalt caused an increase in the asphalt stiffness. Based on Figure 3(c) and (d), It is found that the softening point and $135^{\circ} \mathrm{C}$ viscosity increase in the presence of the ATH; for example, when the $6 \% \mathrm{ATH}$ is added to the matrix asphalt, the softening point and viscosity value increase by $11.1 \%$ and $26.7 \%$, respectively. Such an increase in softening point and viscosity also indicates that the stiffness increases due to the incorporation of ATH.

Furthermore, $G^{*} / \sin \delta$ was also measured and calculated through the DSR to characterize the hightemperature rutting resistance. Based on Figure 3(e), the ATH modified asphalt has higher $G^{*} / \sin \delta$ than that of control asphalt, while $G^{*} / \sin \delta$ of all asphalt samples shows an increasing trend in different temperatures following the increase of the ATH contents. For example, when the temperature is $58^{\circ} \mathrm{C}, G^{*} / \sin \delta \mathrm{s}$ of ATH modified asphalt and control asphalt are $13.19 \mathrm{kPa}$ and $11.07 \mathrm{kPa}$, respectively. This means that the ATH is useful to enhance high-temperature stability.

In addition, although $G^{*} / \sin \delta$ is different at various test temperatures, it is interestingly found that $G^{*} / \sin \delta$ variation range is similar in the same temperature range. For instance, when the temperature increases from $58^{\circ} \mathrm{C}$ to $82^{\circ} \mathrm{C}$ by a $6^{\circ} \mathrm{C}$ increment, $G^{*} / \sin \delta$ of $6 \%$ ATH modified asphalt decreases by $43 \%$ $\left(58^{\circ} \mathrm{C}\right.$ to $\left.64^{\circ} \mathrm{C}\right), 36.4 \%\left(64^{\circ} \mathrm{C}\right.$ to $\left.70^{\circ} \mathrm{C}\right), 37.1 \%\left(70^{\circ} \mathrm{C}\right.$ to $\left.76^{\circ} \mathrm{C}\right)$, and $33.5 \%,\left(76^{\circ} \mathrm{C}\right.$ to $\left.82^{\circ} \mathrm{C}\right)$, respectively, while $G^{*} / \sin \delta$ decreases by $41.4 \%\left(58^{\circ} \mathrm{C}\right.$ to $\left.64^{\circ} \mathrm{C}\right)$, $37.9 \%\left(58^{\circ} \mathrm{C}\right.$ to $\left.70^{\circ} \mathrm{C}\right), 35.9 \%\left(58^{\circ} \mathrm{C}\right.$ to $\left.76^{\circ} \mathrm{C}\right)$, and $33.4 \%\left(58^{\circ} \mathrm{C}\right.$ to $\left.82^{\circ} \mathrm{C}\right)$ for the control asphalt. This indicates that although the ATH increases $G^{*} / \sin \delta$ of asphalt, the thermal property of asphalt seems to remain unchanged.

Meanwhile, the flame-retardant of ATH modified asphalt is checked, and the Limiting Oxygen Index 


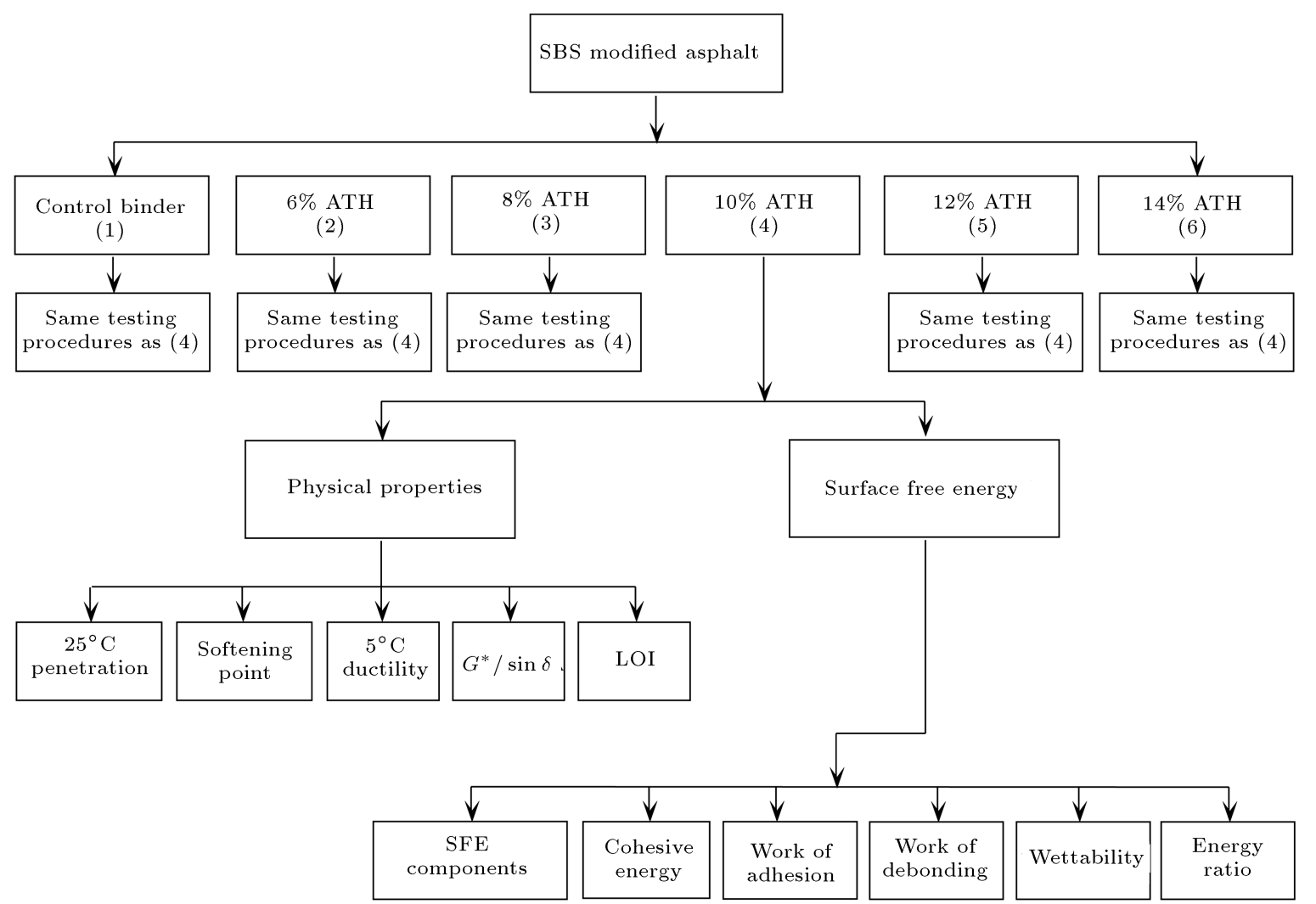

Figure 2. Flow chart of the experimental organization.

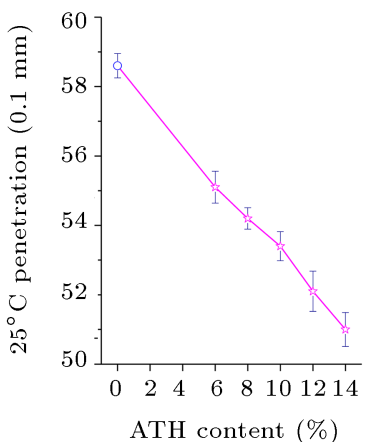

(a)

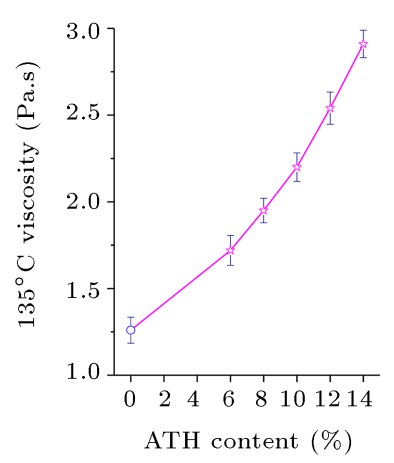

(d)

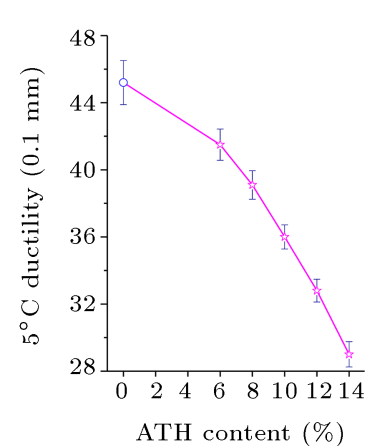

(b)

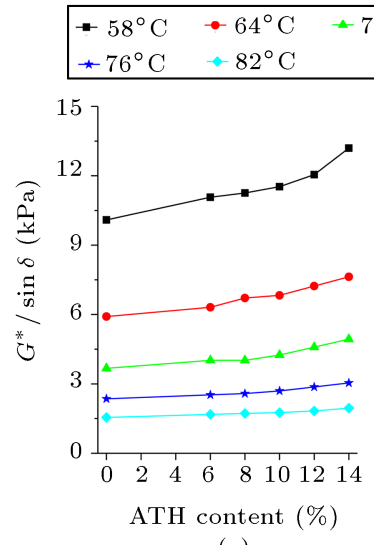

(e)

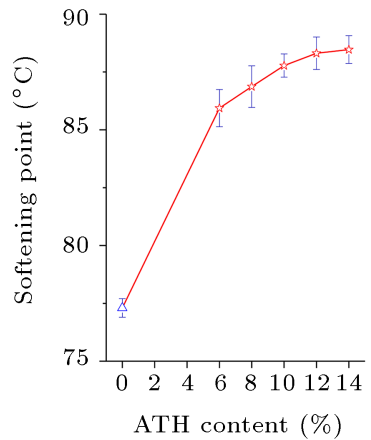

(c)

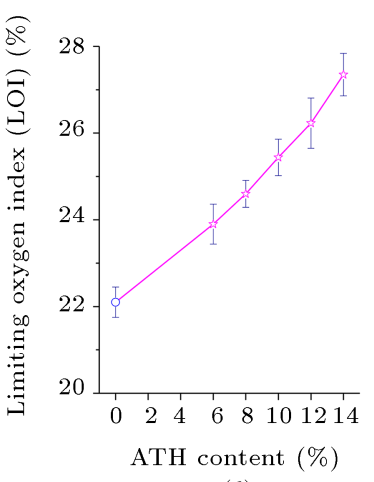

(f)

Figure 3. Physical properties and flame-retardant data: (a) Penetration, (b) ductility, (c) softening point, (d) viscosity, (e) $G^{*} / \sin \delta$, and (f) limiting oxygen index. 
(LOI) is used as the evaluation index. According to Figure 3(f), it can be found that the LOI increases owing to the addition of ATH. For the control asphalt, the LOI is nearly $22 \%$; when the $14 \%$ ATH is added, the LOI value of the samples increases to $27 \%$. The flame retardance has better functionality when the LOI is higher, meaning that ATH makes the asphalt function better and, thus, have better flame retardancy.

\subsection{SFE components and cohesive energy of asphalt binder analysis}

Contact angle can directly demonstrate the wetting ability of the probe liquid with a solid. Table 5 and Figure 4 show the contact angles of asphalt samples measured with the probe liquids. The results in Figure 4 reveal that the contact angles increased when $6 \% \mathrm{ATH}$ was added to the asphalt. However, the contact angles decreased for three probe liquids by increasing ATH contents. When the ATH content is

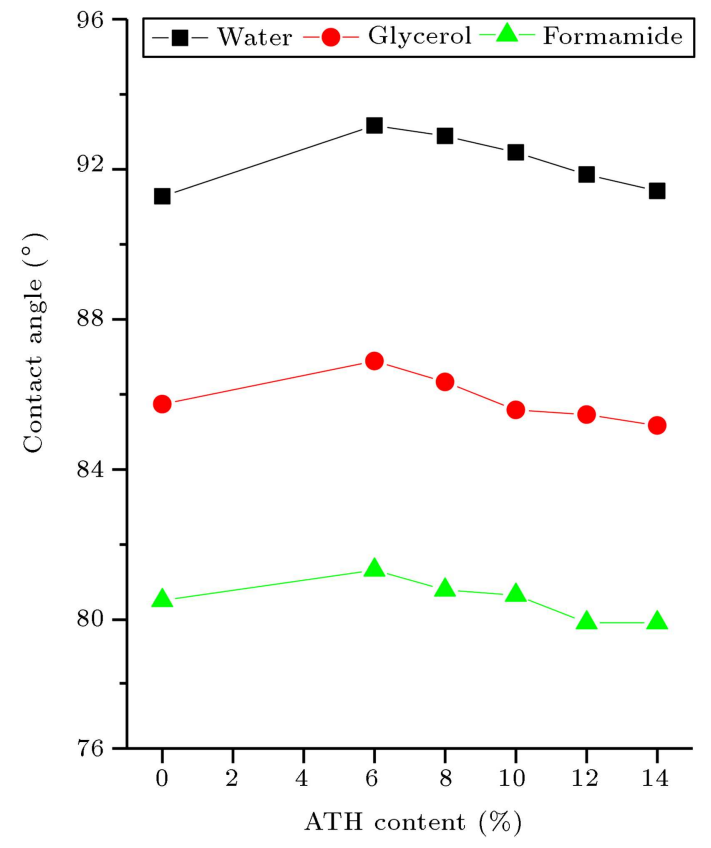

Figure 4. ATH content in contact angle.
$14 \%$, the contact angles are almost the same as those of control asphalt; for example, the contact angle between control asphalt and distilled water is $91.28^{\circ}$, while it is $91.42^{\circ}$ for the $14 \%$ ATH binder. The results are similar for the other probe liquids. Therefore, using a higher amount of ATH content does not appear to affect the contact angle.

Figure 5 shows the results of the surface layer energy of asphalt sample investigations, obtained from the calculation result using Eq. (5). The non-polar SFE component $\left(\gamma^{L W}\right)$ value of asphalt increases with the addition of $6 \%$ to $10 \% \mathrm{ATH}$; however, when the ATH content is above $10 \%$, its value reduces. A reverse trend was observed, such that the acid-base component $\left(\gamma^{A B}\right)$ decreased following the increase of the ATH content by $10 \%$. The nonpolar molecule $\left(\gamma^{L W}\right)$ of asphalt is considered as a solvent for polar molecules, which has a relationship with the elastic properties of asphalt. In general, higher $\gamma^{L W}$ will lead to higher adhesion work. According to the results shown in

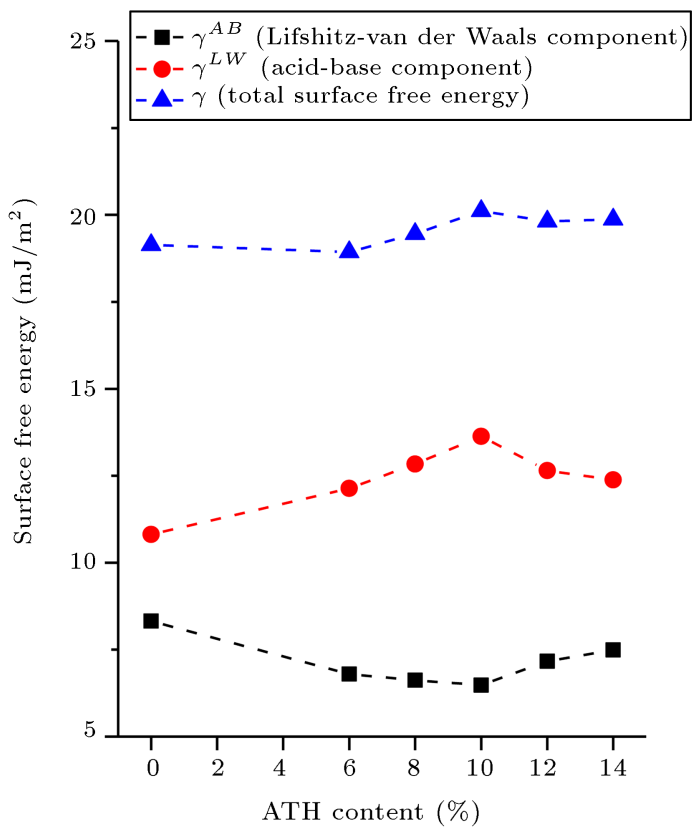

Figure 5. ATH content in SFE.

Table 5. Contact angle of SBS modified binders containing ATH.

\begin{tabular}{|c|c|c|c|c|c|c|}
\hline \multirow[b]{3}{*}{ Samples sources } & \multicolumn{6}{|c|}{ Contact angle $\left({ }^{\circ}\right)$ in liquid } \\
\hline & \multicolumn{2}{|c|}{ Distilled water } & \multicolumn{2}{|c|}{ Glycerol } & \multicolumn{2}{|c|}{ Formamide } \\
\hline & Mean & C.V. & Mean & SD & Mean & SD \\
\hline Control asphalt (C) & 91.28 & 0.18 & 85.74 & 0.13 & 80.51 & 0.12 \\
\hline $\mathrm{C}+6 \%$ ATH & 93.17 & 0.21 & 86.89 & 0.15 & 81.32 & 0.17 \\
\hline $\mathrm{C}+8 \%$ ATH & 92.89 & 0.74 & 86.33 & 0.33 & 80.79 & 0.62 \\
\hline $\mathrm{C}+10 \%$ АТH & 92.45 & 0.31 & 85.59 & 0.35 & 80.65 & 1.12 \\
\hline $\mathrm{C}+12 \%$ АTH & 91.86 & 0.25 & 85.46 & 0.41 & 79.92 & 0.66 \\
\hline $\mathrm{C}+14 \%$ АТН & 91.42 & 0.46 & 85.17 & 1.18 & 79.92 & 0.59 \\
\hline
\end{tabular}




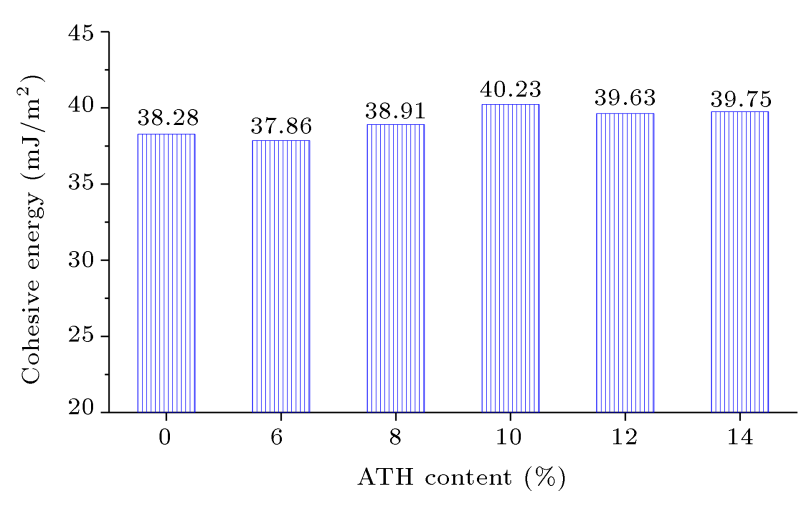

Figure 6. ATH content in cohesive energy.

Figure $4, \gamma^{L W}$ experienced an increase as the ATH content increased by $10 \%$, while $\gamma^{L W}$ decreased in the higher ATH contents (12\% and 14\%). Thus, it can be inferred that the asphalt with lower ATH contents $(<10 \%)$ has better adhesion. Overall, the total surface free energy has achieved insignificant improvement with an increase in ATH content.

The work of cohesion $\left(W_{l l}^{c}\right)$ provides energy for materials so that they can attract each other due to their nature of mutual attraction. In general, a larger cohesive energy bond impedes crack propagation. Because the value of the cohesive energy is twice that of the total SFE, Eq. (6) can be used to calculate it:

$$
W_{l l}^{c}=2 \gamma_{l}
$$

Figure 6 illustrates the work of cohesion of the binders containing different ATH contents. Similar to the changes in the trend of the total SFE, it can be found that the work of cohesion has undergone a slight increase due to the addition of ATH agents. Since higher work of cohesion will lead to greater external energy for crack propagation, these results demonstrate that ATH agents increase the interfacial adhesion of binders, although the improvement may be very insignificant.

\subsection{Work of adhesion and debonding analysis} The work of adhesion can provide necessary energy for asphalt stripping to form the aggregate interface, characterizing the bond strength of asphalt-aggregate system. In general, to obtain a better bond for the asphalt-aggregate system, greater adhesion is desired. In terms of the SFE theory, the work of adhesion under dry conditions can be calculated through Eq. (7):

$$
W_{d r y}^{a}=\gamma_{l}+\gamma_{s}-\gamma_{l s}=2 \sqrt{\gamma_{l}^{L W} \gamma_{s}^{L W}}+2 \sqrt{\gamma_{l}^{A B} \gamma_{s}^{A B}} .
$$

Figure 7 shows the adhesion work of the asphaltaggregate system with different ATH contents. As can be seen in Figure 7, for all tested aggregates, the work of adhesion for the binder samples decreases in

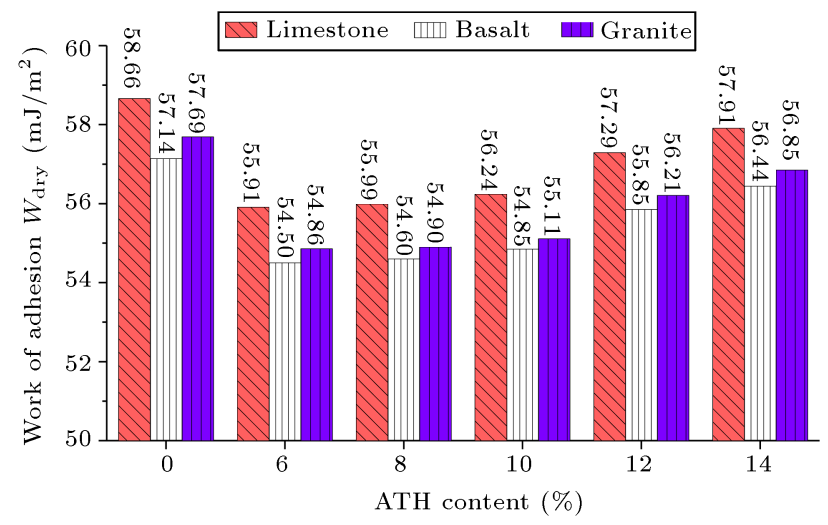

Figure 7. ATH content in work of adhesion.

ATH contents of $6 \%$ to $10 \%$, while an increase in higher ATH contents is detected in $12 \%$ and $14 \%$ range, compared to the control asphalt. In addition, the work of adhesion of ATH modified binders is lower than that of control asphalt. Therefore, it can be concluded that the addition of ATH may weaken the work of adhesion, especially the low amounts of ATH $6 \%$ $10 \%)$. Furthermore, among the three tested aggregates, the limestone-asphalt system has the highest adhesion energy and the basalt-asphalt system has the lowest adhesion energy in different ATH contents, meaning that the bond strength of the limestone-asphalt system is at its highest in the absence of water. According to the findings of previous studies, the fracture energy is associated with the work of adhesion of asphalt mixture, and a decrease in adhesion will lead to an exponential increase in the fracture energy [40]. Therefore, the results of this study show that the addition of ATH will weaken the fracture resistance and further reduce the moisture damage resistance of asphalt mixture.

The work of debonding $\left(W_{\text {wet }}\right)$ is another designation of adhesion work in the presence of moisture, which characterizes the energy for the binder to be separated from aggregate interface in wet conditions.

In terms of thermodynamics, asphalt is prone to stripping when debonding work is higher. Therefore, in order to find better resistance to moisture for the asphalt mixture, a low $W_{\text {wet }}$ is desired. On the basis of the Young-Dupre equation and SFE theory, the work of debonding can be estimated through Eq. (8):

$$
\begin{aligned}
W_{\text {wet }}^{a}= & \gamma_{w l}+\gamma_{w s}-\gamma_{l s}=2\left(\gamma_{\text {water }}+\sqrt{\gamma_{l}^{L W} \gamma_{s}^{L W}}\right. \\
& +\sqrt{\gamma_{l}^{A B} \gamma_{s}^{A B}}-\sqrt{\gamma_{l}^{L W} \gamma_{w}^{L W}}-\sqrt{\gamma_{l}^{A B} \gamma_{w}^{A B}} \\
& \left.-\sqrt{\gamma_{s}^{L W} \gamma_{w}^{L W}}-\sqrt{\gamma_{s}^{A B} \gamma_{w}^{A B}}\right) .
\end{aligned}
$$

Figure 8 shows the work of debonding of the asphalt- 


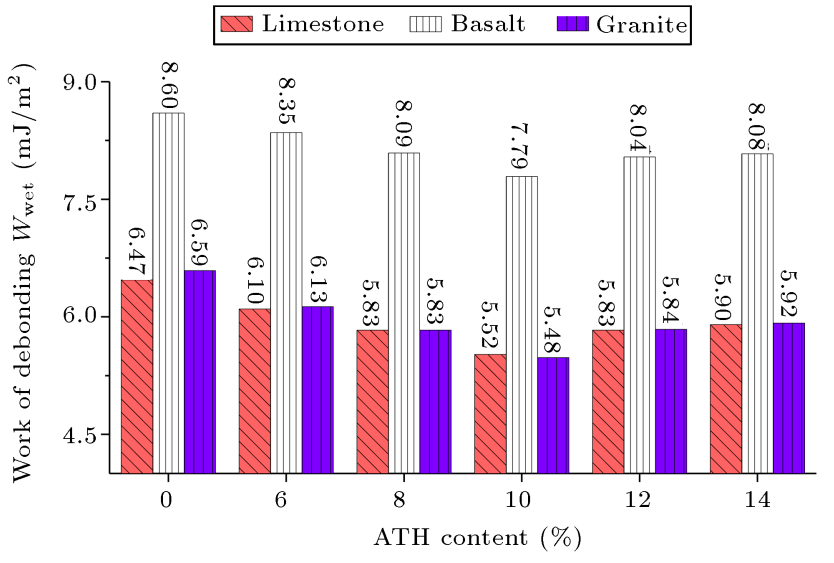

Figure 8. ATH content in work of debonding.

aggregate system with different ATH contents. It is seen that the results of debonding work are similar to those of the adhesion work; the work of debonding for the asphalt samples decreases in ATH contents of $6 \%$ to $10 \%$, while it increases in higher ATH contents (12\% and $14 \%$ ), compared with the control asphalt. In addition, the entire work of debonding of ATH modified binders is lower than that of control asphalt. In addition, basalt showed the highest value of $W_{\text {wet }}$, and limestone and granite showed a similar $W_{\text {wet }}$. For example, the $W_{\text {wet }}$ for bastle is $8.08 \mathrm{~mJ} / \mathrm{m}^{2}$, whereas it is $5.9 \mathrm{~mJ} / \mathrm{m}^{2}$ for limestone in the case of $14 \% \mathrm{ATH}$ binder.

The analysis of variance (ANOVA) was performed through the SPSS program to verify whether a significant difference among the test binders existed or not. The primary independent variables included the ATH contents $(0 \%, 6 \%, 8 \%, 10 \%, 12 \%$, and 14\%) and aggregate types (limestone, basalt, and granite); the dependent variables included the work of adhesion and debonding. By using ANOVA, the statistical significance of the change in the work of adhesion and debonding was examined, the results of which are shown in Tables 6 and 7, respectively. Based on the $p$-values for the significant variables, both ATH contents and the aggregate types are of significant factors. It can thus be stated that the addition of the ATH significantly reduced the adhesion and debonding work.

\subsection{Wettability and energy ratio analysis}

The wettability of a liquid material is considered as a property to wet a solid surface, and it also reflects the energy of a solid surface to reduce the surface tension of a liquid material. In general, it is easy for the asphalt to adhere to the aggregate surface if the wettability is higher. Since the physical and chemical properties of the asphalt and aggregates are different, it is not very easy to wet each other. When the ATH is added, the asphalt may have more difficulty wetting the aggregate surface; thus, it is necessary to assess the wettability between aggregate and asphalt with different amounts of ATH. According to the research of Alvarez et al. [41], the wettability can be represented by the Spreading

Table 6. ANOVA analysis of the work of adhesion at a confidence level of $95 \%$.

\begin{tabular}{lccccc}
\hline Sources of variance & Sum of squared & DF & Mean square & $\boldsymbol{F}$ statistic & $\boldsymbol{P}$ value \\
\hline Model corrected & 25.900 & 7 & 3.700 & 1412.214 & 0.000 \\
Intercept & 56784.500 & 1 & 56784.500 & 21673473.282 & 0.000 \\
ATH content & 19.232 & 5 & 3.846 & 1468.081 & 0.000 \\
Aggregate type & 6.668 & 2 & 3.334 & 1272.545 & 0.000 \\
Errors & 0.026 & 10 & 0.003 & & \\
Total & 56810.426 & 18 & & & \\
Total corrected & 25.926 & 17 & & & \\
\hline
\end{tabular}

Table 7. ANOVA analysis of the work of debonding at a confidence level of $95 \%$.

\begin{tabular}{lccccc}
\hline Sources of variance & Sum of squared & DF & Mean square & $\boldsymbol{F}$ statistic & $\boldsymbol{P}$ value \\
\hline Model corrected & 21.012 & 7 & 3.002 & 1092.867 & 0.000 \\
Intercept & 805.208 & 1 & 805.208 & 293158.416 & 0.000 \\
ATH content & 1.562 & 5 & 0.312 & 113.771 & 0.000 \\
Aggregate types & 19.450 & 2 & 9.725 & 3540.607 & 0.000 \\
Errors & 0.027 & 10 & 0.003 & & \\
Total & 826.248 & 18 & & & \\
Total corrected & 21.040 & 17 & & & \\
\hline
\end{tabular}




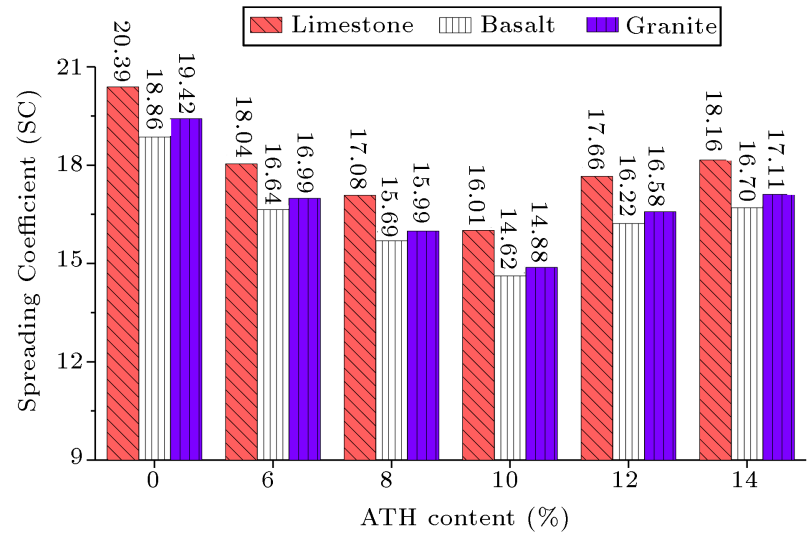

Figure 9. ATH content in spreading coefficients.

Coefficient (SC) as in Eq. (9):

$$
\mathrm{SC}=W_{\mathrm{dry}}^{a}-W_{l l}^{c} .
$$

Figure 9 illustrates the Spreading Coefficients (SC) of asphalt-aggregate systems with different ATH contents and aggregate types. For the three test aggregates, the SC of asphalt samples first decreases in lower ATH contents $(<10 \%)$ and, then, increase in higher ATH contents $(12 \%$ and $14 \%)$. In addition, all spreading coefficients of asphalt samples with ATH are lower than those of the control asphalt, meaning that ATH exerts negative effects on the aggregate coating with a binder. Therefore, it can be inferred that the addition of ATH leads to adverse effects on the bond strength of the asphalt-aggregate system, which will cause high moisture damage potential for asphalt mixture. Furthermore, limestone and basalt have the highest and lowest spreading coefficient values, respectively.

With respect to the entire wettability and work of debonding, the Energy Ratio (ER) parameter was put forward under NCHRP 9-37 research project as a parameter that assesses the compatibility of asphaltaggregate system in the presence of moisture or water. Then, Howson et al. [42] and Little and Bhasin [43] combined the cohesive and adhesive energies into a single term, as shown in Eq. (10). In general, a higher ER value represents better moisture resistance for the asphalt-aggregate system.

$$
E R=\frac{\mathrm{SC}}{W_{\mathrm{wet}}^{a}} .
$$

The ER values were determined for different combinations of ATH contents $(0 \%, 6 \%, 8 \%, 10 \%, 12 \%$, and $14 \%$ ) and different aggregate types (limestone, basalt, and gravel). It is evident from Figure 10 that, for all tested aggregates, the ER value decreases following ATH content increase. Furthermore, the control asphalt has higher ER than that of binders containing different ATH contents. Therefore, it can be inferred that the ATH additive has a negative

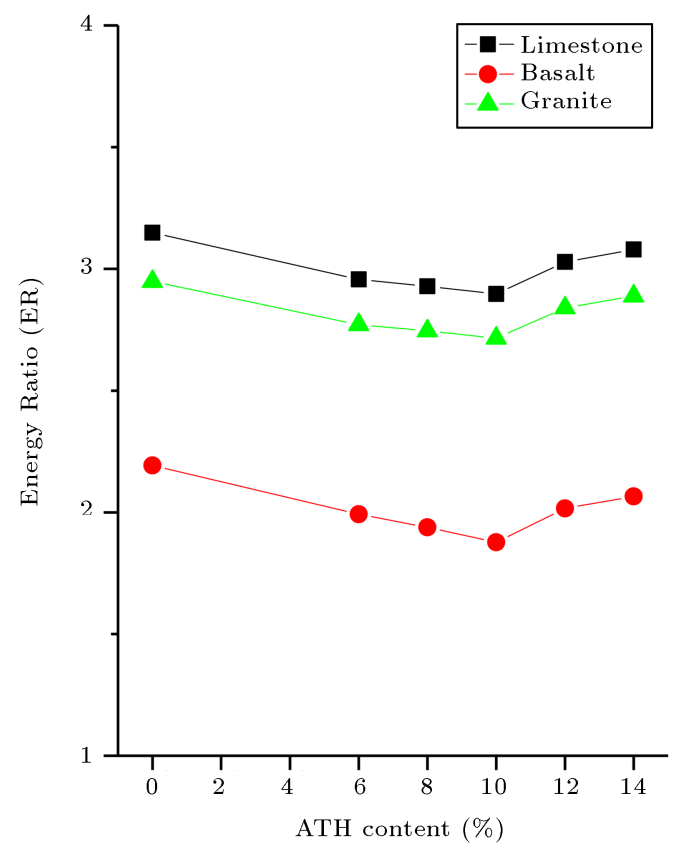

Figure 10. ATH content in energy ratio.

effect on the resistance of the moisture-induced damage potential. The addition of $10 \%$ ATH resulted in the lowest ER value for all tested aggregates. For instance, the ER values of asphalt with basalt aggregate and control asphalt with $10 \%$ ATH binder are 3.15 and 2.89, respectively. Moreover, the ER of asphalt with limestone is higher than that of other aggregate types, while the ER of asphalt with basalt is the lowest. This means that limestone has the best resistance to moisture-induced damage.

The ANOVA was also used to examine the statistical significance of wettability and energy ratio for tested asphalt samples. Based on the $p$-values of the significant variables in Tables 8 and 9 , the amount of ATH content is a significant factor that affects the spreading coefficient and energy ratio. Therefore, it can be stated that the addition of the ATH significantly reduced the moisture damage resistance potential. These results of wettability and energy ratio are consistent with the discussion of the adhesion and debonding work.

\section{Summary and conclusions}

In this research, the moisture susceptibility of the asphalt with flame retardant was evaluated. SBS modified asphalt was used as the matrix asphalt to prepare the samples with a set percentage of ATH $(0 \%$, $6 \%, 8 \%, 10 \%, 12 \%$, and $14 \%$ ). Then, the penetration test $\left(25^{\circ} \mathrm{C}\right)$, softening point, ductility $\left(5^{\circ} \mathrm{C}\right)$, viscosity, $G^{*} / \sin \delta$, and limiting oxygen index were tested to inspect the physical and flame-retardant properties, while the surface free energy characteristics including 
Table 8. ANOVA analysis of the spreading coefficient at a confidence level of $95 \%$.

\begin{tabular}{lccccc}
\hline Sources of variance & Sum of squared & DF & Mean square & $\boldsymbol{F}$ statistic & $\boldsymbol{P}$ value \\
\hline Model corrected & 38.481 & 7 & 5.497 & 1950.146 & 0.000 \\
Intercept & 5237.420 & 1 & 5237.420 & 1857973.228 & 0.000 \\
ATH content & 31.829 & 5 & 6.366 & 2258.283 & 0.000 \\
Aggregate type & 6.651 & 2 & 3.326 & 1179.805 & 0.000 \\
Errors & 0.028 & 10 & 0.003 & & \\
Total & 5275.929 & 18 & & & \\
Total corrected & 38.509 & 17 & & & \\
\hline
\end{tabular}

Table 9. ANOVA analysis of the energy ratio at a confidence level of $95 \%$.

\begin{tabular}{lccccc}
\hline Sources of variance & Sum of squared & DF & Mean square & $\boldsymbol{F}$ statistic & $\boldsymbol{P}$ value \\
\hline Model corrected & 3.482 & 7 & 0.497 & 1971.913 & 0.000 \\
Intercept & 123.036 & 1 & 123.036 & 487806.960 & 0.000 \\
ATH content & 0.141 & 5 & 0.028 & 111.894 & 0.000 \\
Aggregate types & 3.340 & 2 & 1.670 & 6621.960 & 0.000 \\
Errors & 0.003 & 10 & 0.000 & & \\
Total & 126.520 & 18 & & & \\
Total corrected & 3.484 & 17 & & & \\
\hline
\end{tabular}

SFE components, cohesion energy, work of adhesion, work of debonding, wettability, and energy ratio were selected to evaluate moisture damage resistance. Based on the experimental results and previous discussions, the conclusions can be drawn as follows:

1. The results of physical and flame-retardant tests showed that the addition of ATH to asphalt could increase the viscosity, softening point, $G^{*} / \sin \delta$, and limiting oxygen index, indicating that ATH modified binder has better rutting resistance and flame resistance. However, the decrease of penetration and ductility means that $\mathrm{ATH}$ will reduce the low-temperature performance of asphalt;

2. The contact angles of ATH modified binders exhibited incensement in the lower amounts (i.e., $6 \%$ ATH) and, then, decreased with increasing ATH content, while the acid SFE component (polar component) and total SFE component had incensement with the addition of ATH. These changes of SFE components showed that the addition of ATH would affect the moisture sensitivity of asphalt;

3. Results of the work of cohesion, work of adhesion, and work of debonding showed that ATH could improve the interfacial adhesion of binders, but reduce the bond strength between aggregates and asphalt binder systems under dry and wet conditions. This shows that the addition of ATH may decrease the water resistance of asphalt;
4. It was observed that the spreading coefficients and energy ratio of ATH modified asphalt were lower than those of the control binders, although these values had a slight increase in higher amounts of ATH, (i.e., $12 \%$ and $14 \%$ ). Such a decrease showed that high moisture induced damage potential in the mix as the addition of ATH;

5. The results of this study proved that the addition of ATH would weaken the moisture resistance of asphalt in terms of micromechanisms. Moreover, the recommended percentage of ATH was $6-8 \%$ with regard to physical properties, flame retardation, and moisture susceptibility for the test asphalt and aggregates.

\section{Acknowledgments}

The research presented herein was sponsored by the Fundamental Research Funds for the Central Universities (2019B13214), by the Foundation of Guangxi Key Laboratory of Road Structure and Materials (2015gxjgclkf-005), and by the National Natural Science Foundation of China (51908194).

\section{References}

1. Mei, F., Tang, F., Ling, X., and Yu, J. "Evolution characteristics of fire smoke layer thickness in a mechanical ventilation tunnel with multiple point 
extraction", Applied Thermal Engineering, 111, pp. 248-256 (2017).

2. Li, X., Zhou, Z., Deng, X., and You, Z. "Flame resistance of asphalt mixtures with flame retardants through a comprehensive testing program", Journal of Materials in Civil Engineering, 29(4), 04016266 (2016).

3. M.O.T. "2015 transportation industry development statistics bulletin", Report 2016-00375, Beijing, China (2016).

4. Fan, C.G. and Tang, F. "Flame interaction and burning characteristics of abreast liquid fuel fires with cross wind", Experimental Thermal and Fluid Science, 82, pp. 160-165 (2017).

5. Tian, X., Zhong, M., Shi, C., Zhang, P., and Liu, C. "Full-scale tunnel fire experimental study of fireinduced smoke temperature profiles with methanolgasoline blends", Applied Thermal Engineering, 116, pp. 233-243 (2017).

6. Du, F., Okazaki, K., and Ochiai, C. "Disaster coping capacity of a fire-prone historical dong village in China: A case study in Dali village, Guizhou", International Journal of Disaster Risk Reduction, 21, pp. 85-98 (2017).

7. Khattri, S.K. "From small-scale tunnel fire simulations to predicting fire dynamics in realistic tunnels", Tunnelling and Underground Space Technology Incorporating Trenchless Technology Research, 61, pp. 198-204 (2017).

8. Liu, Y., Wang, Y., and Li, D. "Estimation and uncertainty analysis on carbon dioxide emissions from construction phase of real highway projects in China", Journal of Cleaner Production, 144, pp. 337-346 (2017).

9. Xu, T., Huang, X., and Zhao, Y. "Investigation into the properties of asphalt mixtures containing magnesium hydroxide flame retardant", Fire Safety Journal, 46(6), pp. 330-334 (2011).

10. Seike, M., Kawabata, N., and Hasegawa, M. "Quantitative assessment method for road tunnel fire safety: Development of an evacuation simulation method using CFD-derived smoke behavior", Safety Science, 94, pp. 116-127 (2017).

11. Pei, J., Wen, Y., Li.Y., Shi, X., Zhang, J.P., Li, R., and Du, Q.L. "Flame-retarding effects and combustion properties of asphalt binder blended with organo montmorillonite and alumina trihydrate", Construction and Building Materials, 72, pp. 41-47 (2014).

12. Puente, E., Lázaro, D., and Alvear, D. "Study of tunnel pavements behaviour in fire by using coupled cone calorimeter - FTIR analysis", Fire Safety Journal, 81, pp. 1-7 (2016).

13. Qiu, S., Wang, X., Yu, B., Feng, X.M., Mu, X.W., Richard, K.K., and Hu, Y.Y. "Flame-retardantwrapped polyphosphazene nanotubes: A novel strategy for enhancing the flame retardancy and smoke toxicity suppression of epoxy resins", Journal of Hazardous Materials, 325, pp. 327-339 (2017).
14. Wu, K., Zhu, K., Kang, C., Wu, B., and Huang, Z. "An experimental investigation of flame retardant mechanism of hydrated lime in asphalt mastics", Materials and Design, 103, pp. 223-229 (2016).

15. Kinateder, M., Muller, M., Jost, M., Mühlberger, A., and Pauli, P. "Social influence in a virtual tunnel fire-Influence of conflicting information on evacuation behavior", Applied Ergonomics, 45(6), pp. 1649-1659 (2014).

16. Li, B., Wen, Y., and Li, X. "Laboratory evaluation of pavement performance and burning behavior of flameretardant asphalt mixtures", Journal of Testing and Evaluation, 45(1), pp. 9-17 (2016).

17. Kiliaris, P. and Papaspyrides, C.D. "Polymer/layered silicate (clay) nanocomposites: An overview of flame retardancy", Progress in Polymer Science, 35(7), pp. 902-958 (2010).

18. Bonati, A., Merusi, F., Bochicchio, G., Tessadri, B., Polacco, G., Filippi, S., and Giuliania, F. "Effect of nanoclay and conventional flame retardants on asphalt mixtures fire reaction", Construction \& Building Materials, 47(10), pp. 990-1000 (2013).

19. Zhang, Y., Pan, X., Sun, Y., Xu, W., Pan, Y.Q., Xie, H.F., and Cheng, R.S. "Flame retardancy, thermal, and mechanical properties of mixed flame retardant modified epoxy asphalt binders", Construction and Building Materials, 68, pp. 62-67 (2014).

20. Cong, P., Chen, S., Yu, J., and Wu, S. "Effects of aging on the properties of modified asphalt binder with flame retardants", Construction \& Building Materials, 24(12), pp. 2554-2558 (2010).

21. Bonati, A., Bochicchio, G., Merusi, F., Polacco, G., and Giuliani, F. "Fire behaviour and heat release properties of asphalt mixtures", International Journal of Pavement Research \& Technology, 6(2), pp. 100-108 (2013).

22. Yin, H., Zhang, Y., Sun, Y., Xu, W., Yu, D., Zhang, Y., and Cheng, R. "Performance of hot mix epoxy asphalt binder and its concrete", Materials and Structures, 48(11), pp. 3825-3835 (2015).

23. Xu, T., Huang, X.M., and Zhao, Y.L. "Choice of pavement type in road tunnel and investigation research", J. Wuhan Univ. Technol. Transport Sci. Eng., 35, pp. 181-184 (2011).

24. Zhang, C., Xu, T., Shi, H., and Wang, L. "Physicochemical and pyrolysis properties of SARA fractions separated from asphalt binder", Journal of Thermal Analysis and Calorimetry, 122(1), pp. 241-249 (2015).

25. Zhang, X., Jiang, Y., and Sugimoto, S. "Seismic damage assessment of mountain tunnel: A case study on the Tawarayama tunnel due to the 2016 Kumamoto earthquake", Tunnelling \& Underground Space Technology, 71, pp. 138-148 (2018).

26. Bhasin, A., Howson, J., Masad, E., Little, D.N., and Lytton, R.L. "Effect of modification processes on bond energy of asphalt binders", Transportation Research Record Journal of the Transportation Research Board, 1998(1), pp. 29-37 (2007). 
27. Qin, X., Zhu, S., Chen. S., Li, Z., and Dou, H. "Flame retardancy of asphalt mixtures and mortars containing composite flame-retardant materials", Road Materials and Pavement Design, 15(1), pp. 66-77 (2014).

28. Hamedi, G.H., Nejad, F.M., and Oveisi, K. "Estimating the moisture damage of asphalt mixture modified with nano zinc oxide", Materials and Structures, 49(4), pp. 1165-1174 (2016).

29. Ghabchi, R., Singh, D., and Zaman, M. "Evaluation of moisture susceptibility of asphalt mixes containing RAP and different types of aggregates and asphalt binders using the surface free energy method", Constr. Build. Mater., 73, pp. 479-489 (2014).

30. Xu, G. and Wang, H. "Study of cohesion and adhesion properties of asphalt concrete with molecular dynamics simulation", Computational Materials Science, 112, pp. 161-169 (2016).

31. Hefer, A., Little, D., and Lytton, R. "A synthesis of theories and mechanisms of bitumen-aggregate adhesion including recent advances in quantifying the effects of water", Association of Asphalt Paving Technologists, 74, pp. 139-196 (2005).

32. Aguiar Moya, J.P., Salazar Delgado, J., Baldi Sevilla, A., Leivavillacorta, F., and Loriasalazar, L. "Effect of aging on adhesion properties of asphalt mixtures with the use of bitumen bond strength and surface energy measurement tests", Transportation Research Record: Journal of the Transportation Research Board, 2505, pp. 57-65 (2015).

33. Moraes, R., Velasquez, R., and Bahia, H. "Using bond strength and surface energy to estimate moisture resistance of asphalt-aggregate systems", Construction \& Building Materials, 130, pp. 156-170 (2016).

34. Abandansari, H.F. and Amir, M. "Investigating effects of using nanomaterial on moisture susceptibility of hot-mix asphalt using mechanical and thermodynamic methods", Construction and Building Materials, 131, pp. 667-675 (2017).

35. M.O.T., Standard Test Methods of Bitumenand Bituminous Mixtures for Highway Engineering, China Communications Press, Beijing (2011).

36. Oss, C.J.V., Chaudhury, M.K., and Good, R.J. "Interfacial Lifshitz-van der Waals and polar interactions in macroscopic systems", Chemical Reviews, 88(6), pp. 927-941 (1988).

37. Cheng, D., Little, D.N., Lytton, R.L., and Holste, J.C. "Use of surface free energy of asphalt-aggregate system to predict moisture damage potential", Journal of the Association of Asphalt Paving Technologists, 71, pp. 59-88 (2002).

38. Owens, D.K. and Wendt, R.C. "Estimation of the surface free energy of polymers", Journal of Applied Polymer Science, 13(8), pp. 1741-1747 (1969).
39. Liu, S., Yu, X., and Dong, F. "Evaluation of moisture susceptibility of foamed warm asphalt produced by water injection using surface free energy method", Construction and Building Materials, 131, pp. 138-145 (2017).

40. Al-Qadi, I.L., Abu-Lebdeh, T., and Masson, J.F. "Use of surface energy to evaluate adhesion of bituminous crack sealants to aggregates", American Journal of Engineering \& Applied Sciences, 4(2), pp. 244-251 (2011).

41. Alvarez, A.E., Ovalles, E., and Martin, A.E. "Comparison of asphalt rubber-aggregate and polymer modified asphalt-aggregate systems in terms of surface free energy and energy indices", Construction \& Building Materials, 35(10), pp. 385-392 (2012).

42. Howson, J., Masad, E.A., Bhasin, A., Branco, V.C., Arambula, E., Lytton, R.L., and Little, D.N. "System for the evaluation of moisture damage using fundamental material properties", Report 0-4524-1, Texas Transportation Institute, Texas A\&M University (2007).

43. Little, D.N. and Bhasin, A. "Using surface energy measurements to select materials for asphalt pavement", NCHRP Project, 9-37, Transportation Research Board (2006).

\section{Biographies}

Shengjie Liu received his $\mathrm{PhD}$ in Road Engineering from the University of Chang'an in 2015. He is an Assistant Professor in Civil Engineering and Transportation at Hohai University since 2015. Dr. Liu has 10 years of practical and research experience in pavement engineering and materials. In his career, he has completed research projects in a wide range of subjects including pavement mechanistic design, warm mix asphalt, rubber asphalt, micromechanics based models for pavement materials, and bio asphalt.

Shengbo Zhou received his $\mathrm{PhD}$ in Road Engineering from the University of Chang'an in 2014. He is a Senior Engineer in Guangxi Transportation Research Institute. In his career, he has completed research projects in a wide range of subjects including pavement mechanistic design, warm mix asphalt, and pavement management.

Yinshan Xu received his $\mathrm{PhD}$ in Road Engineering from the University of Chang'an in 2017. He is a Senior Engineer in Zhejiang Scientific Research Institute of Transport. In his career, he has completed research projects in a wide range of subjects including pavement mechanistic design, pavement detection, and pavement maintenance. 